\title{
A combined surface- and volume-scattering model for ice-sheet radar altimetry
}

\author{
Curt H. Davis \\ Electrical and Computer Engineering, University of Missouri-Truman Campus, Independence, Missouri 64050, U.S.A. \\ RICHARD K. MOORE \\ Radar Systems and Remote Sensing Laboratory, University of Kansas, Lawrence, Kansas 66045, U.S.A.
}

\begin{abstract}
Over the last 15 years, satellite-altimeter data have been used to produce surface-elevation maps of the Greenland and Antarctic ice sheets with a $2 \mathrm{~m}$ accuracy. Analysis of Seasat and Geosat cross-over points showed that satellite altimeters can measure changes in the mass balance of the ice sheets. The retracking algorithm used to extract surface elevations from Seasat and Geosat return wave forms is based upon a modified form of the Brown surface-scattering model. Recent work has shown that altimeter wave forms over higher-altitude regions of the ice sheets are affected by sub-surface volume-scattering. Here, we develop a theoretical model for altimeter return wave forms over the ice sheets that is based on a combination of surface- and volume-scattering. By approximating the altimeter's antenna pattern and transmitted pulse shape with Gaussian functions, we derive a closed-form analytical solution for the return-power volume-scattered from beneath the ice-sheet surface. We then combine the volume-scattering model with the Brown model and apply it to average wave forms from the Greenland and Antarctic ice sheets. The results show that the combined model accurately describes variations in altimeter wave-form shapes that are produced by differing contributions of surfaceand volume-scattering to the received power. The combined model is then used to simulate return wave forms from a dual-frequency altimeter. The simulation shows that a two-frequency system can provide quantitative estimates of the absorption and scattering coefficients for near-surface snow.
\end{abstract}

\section{NOTATION}

$A_{\mathrm{e}} \quad$ Effective antenna aperture $\left(\mathrm{m}^{2}\right)$

$A^{\prime \prime} \quad$ Received power amplitude (W)

$\beta$
Two-way beam-width coefficient

Speed of light, $3 \times 10^{8} \mathrm{~m} \mathrm{~s}^{-1}$

Speed of light in snow $\left(\mathrm{m} \mathrm{s}^{-1}\right)$

Depth of penetration $(\mathrm{m})$

Differential shell area

Differential shell thickness

Differential received power

Two-way incremental ranging time

Relative complex dielectric constant of snow

Relative complex dielectric constant of ice

Altimeter frequency

Antenna gain at nadir

One-way beam-width coefficient

Fresnel reflection coefficient

Height of satellite $(\mathrm{m})$

Volume coefficient

Absorption coefficient of snow $\left(\mathrm{m}^{-1}\right)$

Extinction coefficient of snow $\left(\mathrm{m}^{-1}\right)$

Scattering coefficient of snow $\left(\mathrm{m}^{-1}\right)$

Path length in snow (m)

Altimeter free-space wavelength $(\mathrm{m})$

Transmitted power at satellite (W)
$P_{\mathrm{i}} \quad$ Power density incident upon snow surface $\left(\mathrm{W} \mathrm{m}^{-2}\right)$

$P_{\mathrm{t}} \quad$ Power density transmitted across air-snow boundary $\left(\mathrm{W} \mathrm{m}^{-2}\right)$

$P_{\mathrm{FS}} \quad$ Flat-surface impulse response

$P_{\mathrm{r}} \quad$ Received power at satellite $(\mathrm{W})$

$P_{8} \quad$ Average surface-impulse response

$P_{\tau} \quad$ Transmitted pulse profile

$\psi \quad$ Azimuth angle

$r \quad$ Radius of ice grains

$R \quad$ Satellite range (m)

$\rho_{\mathrm{s}} \quad$ Density of snow $\left(\mathrm{Mg} \mathrm{m}^{-3}\right)$

$\rho_{\mathrm{i}} \quad$ Density of ice $\left(\mathrm{Mg} \mathrm{m}^{-3}\right)$

$S(\delta) \quad$ Brown surface-scattering model

$S V(\delta)$ Combined surface-/volume-scattering model

$S W H$ Ocean significant wave height $(\mathrm{m})$

$\sigma_{s} \quad$ r.m.s. surface roughness $(\mathrm{m})$

$\sigma_{\mathrm{vs}} \quad$ Back-scattering cross-section per unit volume $\left(\mathrm{m}^{2} \mathrm{~m}^{-3}\right)$

$t \quad$ Time

$t_{0} \quad$ Round-trip time corresponding to intersection of altimeter pulse with a flat surface

$T \quad$ Power-transmission coefficient

$\theta \quad$ Elevation angle

$\theta_{3 \mathrm{~dB}} \quad$ Half-power beam width of antenna pattern

$V(\delta) \quad$ Volume-scattering model 


\section{INTRODUCTION}

The ice sheets of Greenland and Antarctica constitute $10 \%$ of the surface land area of the Earth, and the accumulated ice comprises $90 \%$ of the global fresh-water reserves. Ice sheets exist as a consequence of climate and are coupled closely with the natural environment through complex exchanges of energy and mass. An understanding of ice-sheet dynamics is a fundamental requirement to achieve a realistic model of climatic and oceanographic processes. Even though the ice sheets play a critical role in global processes, they remain the most poorly explored and little-studied areas on the Earth's surface. Research in the polar regions is hampered by the vast size of the ice sheets, their remoteness and the harshness of the polar environment (Thomas and others, 1985).

Some global-circulation models predict a world-wide temperature increase between 3.0 and $5.5 \mathrm{~K}$ due to doubling in the current levels of carbon dioxide and other greenhouse gases (Schneider, 1989). Also, the models show that the expected climatic warming is more strongly focused in the polar latitudes (Bryan and others, 1982; Schlesinger, 1984; Hansen and others, 1988). Enhanced ice-sheet melting could raise global sea levels, impact the circulation of deep ocean wateres and seriously alter the heat/momentum transfer between the ocean and the atmosphere.

Major changes in the volume of the polar ice sheets relate directly to global sea levels. Because the Greenland and Antarctic ice sheets contain a volume of ice equivalent to $70 \mathrm{~m}$ of sea level, volume changes as small as $1 \%$ are significant. During the last interglacial period, the sea level was $6 \mathrm{~m}$ higher than present-day levels. Mercer (1978) proposed the collapse of the West Antarctic ice sheet as a possible cause of the $6 \mathrm{~m}$ sealevel increase. During the past century, the sea level, as recorded from tide-gauge data around the world, apparently rose by $10-20 \mathrm{~cm}$. Although both thermal expansion of the oceans and ice-sheet melting contribute to sea-level rise, no more than $25 \%$ of this increase can be attributed to thermal expansion (Etkins and Epstein, 1982; Barnett, 1984). The apparent increase met with some skepticism because the rate of sea-level rise exhibited a large geographic variability. However, recent results, which adjust the tide-gauge data to remove contributions of glacial isostatic adjustment to local sea-level trends, show that a globally coherent increase in sea level of $2.4 \pm 0.9$ mm year $^{-1}$ is occurring (Peltier and Tushingham, 1989).

Early indications of a warmer climate in the polar regions are likely to show as ice thinning, increased calving from ice shelves and an inland migration of iceshelf grounding lines (Thomas and others, 1979). Because ice flows along the direction of maximum regional surface slope, elevation data are used to delineate major drainage basins, ice flowlines, ice streams and grounding lines. Moreover, repeated mapping of surface elevations can be used to detect changes in the mass balance (volume growth) of the ice sheets (Zwally in Nye, 1975; Brooks and others, 1978). A positive mass balance is associated with ice-sheet thickening, while a negative mass balance is associated with thinning. Although most mountain glaciers are retreating, there is no consensus as to the behavior of the Greenland and Antarctic ice sheets. Localized field measurements indicate that some regions of the ice sheets are thickening while others are thinning. Systematic monitoring of surface elevations requires accurate repetitive measurements over the millions of square miles that comprise the continental ice sheets.

Even though space-borne altimeters were primarily designed for oceanographic applications, the orbits of Seasat (MacArthur, 1978; Townsend, 1980) and Geosat (MacArthur and others, 1987) extended to latitudes of $\pm 72.1^{\circ}$, covering major parts of the Greenland and Antarctic ice sheets. The European Space Agency's ERS1 satellite altimeter currently covers latitudes up to $\pm 82^{\circ}$. Robin (1966) first proposed satellite altimetry for surveying the ice sheets. Over the last two decades, space-borne altimeters provided the only proven means for measuring surface elevations with the precision and spatial coverage required for meaningful ice-sheet studies (Thomas and others, 1985; Thomas, 1991). Data sets provided by the Geos-3, Seasat and Geosat satellites have been used to produce surface-elevation maps of large parts of Greenland and Antarctica with a $2 \mathrm{~m}$ accuracy (Brooks and others, 1978; Brooks, 1982; Zwally and others, 1983; Bindschadler and others, 1989). This accomplished in a few years what would have taken decades of intensive field surveying to produce. Maps of specific surface features such as ice margins, grounding lines and ice shelves have also been produced (Thomas and others, 1983; Brooks and Norcross, 1984; Cudlip and McIntyre, 1987; Partington and others, 1987; Zwally and others, 1987; Ridley and others, 1989; Stephenson and Zwally, 1989). In addition, the elevation data were used to assess the mass balance of the Jakovshavns Isbræ drainage basin in western Greenland (Bindschadler, 1984).

One of the most important glaciological applications of altimetery data to date was the combined analysis of the Geos-3, Seasat and Geosat data sets, spanning a period of 10 years, to assess the growth of the Greenland ice sheet. By analyzing satellite cross-over points and comparing changes in elevation, Zwally and others (1989) estimated that the southern part of the Greenland ice sheet (south of $72.1^{\circ} \mathrm{N}$ ) grew at an average rate of $23 \mathrm{~cm} \mathrm{year}^{-1}$ from 1978 to 1986 . Zwally (1989) suggested an increase in precipitation rates caused by a warmer polar climate as a possible cause of the mass imbalance. The cross-over analysis demonstrates the ability of satelite-radar altimetry to produce results of global significance.

\section{ALTIMETER PRINCIPLES AND TECHNIQUES}

The satellite-radar altimeter measures the precise time it takes a radiated pulse to travel to the surface and back again. If the orbital position of the satellite is known relative to a reference surface, then the measured time, converted to range, is used to derive the elevation of the reflecting surface. In addition to measuring range, the altimeter records a mean "wave form" consisting of an average of return-pulse echoes (typically 100) and estimates other geophysical parameters such as ocean 
wave height and surface wind speed. Since the Geos-3, Seasat and Geosat satellites were developed primarily for oceanographic applications, all on-board estimation of geophysical parameters uses a model that relates the mean return wave form to back-scattering from the ocean surface. A diagram of the altimeter pulse interaction with a flat surface and the corresponding mean return wave form is shown in Figure 1. As the incident pulse strikes the surface, a circular region that increases linearly with time is illuminated. Correspondingly, a linear increase in the leading edge of the return wave form occurs. After the trailing edge of the radar pulse intersects the surface, the region back-scattering energy to the satellite comes from an expanding annulus of constant area. At this point, the return wave-form amplitude reaches a maximum and begins to trail off due to the reduction of off-vertical scattering by the altimeter's antenna pattern. For a rough ocean surface, the leading edge of the return pulse is "stretched" because scattering from the wave crests precedes scattering from the wave troughs as the pulse wave front progresses downward. Thus, the width of the leading edge of the return pulse is related to the height of ocean waves.

The radar-altimeter model relates the interaction of the return wave form to sea-surface state. Since the backscatter area seen by the altimeter is restricted to a fraction of a degree around vertical, the ocean surface can be

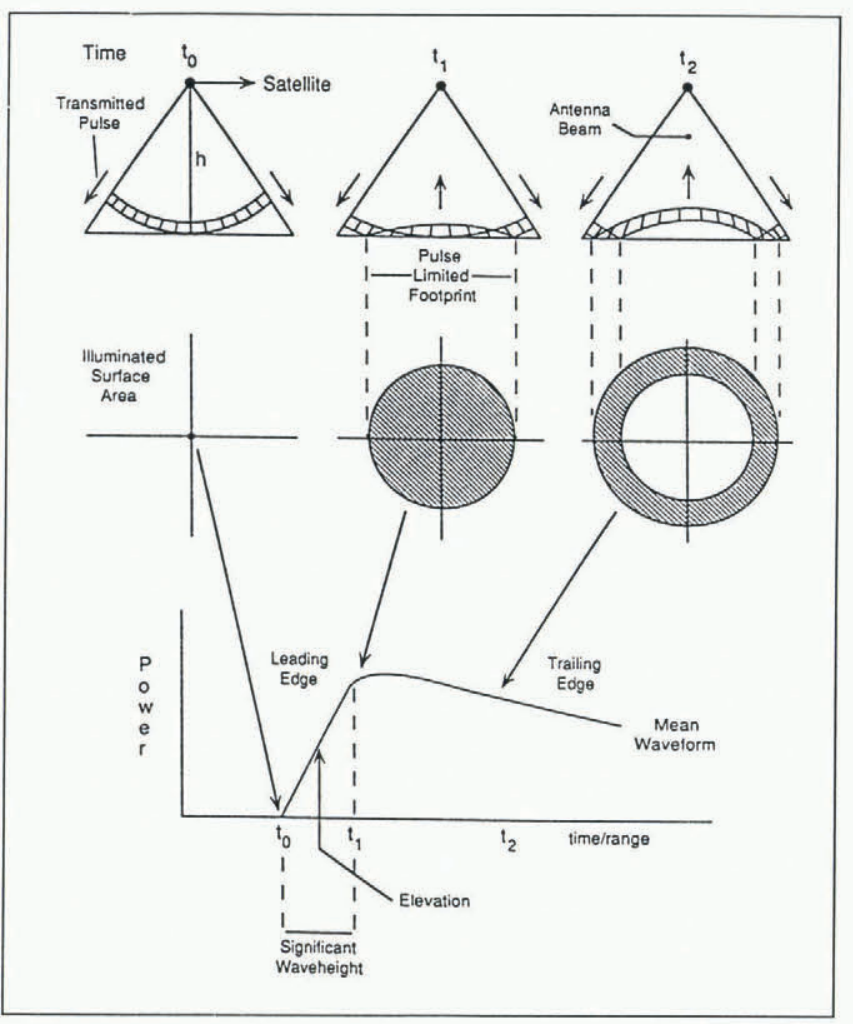

Fig. 1. The interaction of a radar-altimeter pulse with a horizontal and planar surface, from its initial intersection $\left(t_{0}\right)$, through the intersection of the back of the pulse shell with the surface $\left(t_{1}\right)$, to the stage where the pulse begins to be attenuated by the antenna beam $\left(t_{2}\right)$. The return is from the surface only (Ridley and Partington, 1988). approximated by a horizontal planar surface with a large number of scattering facets distributed randomly about the mean sea surface. Moore and Williams (1957) showed that the mean altimeter return wave form as a function of time is described by the convolution of two terms,

$$
\mathrm{P}_{\mathrm{r}}(t)=P_{\tau}(t) \times P_{\mathrm{s}}(t)
$$

where $\mathrm{P}_{\mathrm{r}}(t)$ is the received power at the satellite. $P_{\tau}(t)$ is the transmitted-pulse profile after passing through the altimeter receiver, and $P_{\mathrm{s}}(t)$ is a term involving the distribution of scatterers, their back-scattering properties and the antenna gain. Barrick (1972) used this convolutional form and obtained a double integral describing the altimeter return wave form assuming a Gaussian distribution of scattering facets. Brown (1977) approximated the transmitted pulse shape, the altimeter's antenna pattern and the range distribution of scatterers with Gaussian functions to generate an analytical solution for the mean ocean return.

The mean return wave form given by the Brown surface-scattering model is

$$
\begin{aligned}
& S(\delta)=\frac{1}{2} P_{\mathrm{FS}}(0)\left[1+\operatorname{erf}\left(\frac{\delta}{\sqrt{2} \sigma_{\mathrm{c}}}\right)\right] \quad \text { for } \delta<0 \\
& S(\delta)=\frac{1}{2} P_{\mathrm{FS}}(\delta)\left[1+\operatorname{erf}\left(\frac{\delta}{\sqrt{2} \sigma_{\mathrm{c}}}\right)\right] \quad \text { for } \delta \geq 0
\end{aligned}
$$

The flat-surface impulse response, $P_{\mathrm{FS}}(\delta)$, is given by

$$
P_{\mathrm{FS}}(\delta)=\exp \left[\frac{-4 c \delta}{\gamma h}\right]
$$

where $c$ is the speed of light, $h$ is the height of the satellite and $\delta$ is the two-way incremental ranging time

$$
\delta=t-\frac{2 h}{c} \text {. }
$$

The one-way beam-width coefficient, $\gamma$, is

$$
\gamma=\frac{2 \sin ^{2}\left[\theta_{3 \mathrm{~dB}} / 2\right]}{-\ln 0.5}
$$

where $\theta_{3 \mathrm{~dB}}$ is the half-power beam width of the altimeter's antenna pattern. The parameter $\sigma_{\mathrm{c}}$ is determined from

$$
\sigma_{\mathrm{c}}=\sqrt{\sigma_{\mathrm{p}}{ }^{2}+\left(\frac{2 \sigma_{\mathrm{s}}}{c}\right)^{2}}
$$

where $\sigma_{\mathrm{p}}$ is related to the altimeter's transmitted pulse width, $\tau$, by

$$
\sigma_{\mathrm{p}}=0.425 \tau
$$

and $\sigma_{s}$ is the r.m.s. surface roughness.

All on-board estimation of oceanic geophysical parameters uses the ocean surface-scattering model (e.g. Hancock and others, 1980; Hayne, 1981). Mean oceanreturn wave forms from the Brown model appear in Figure 2, where the family of curves results from varying the r.m.s. surface roughness. For small $\sigma_{s}$, the return wave forms rise sharply to the plateau region and then begin to trail off due to the reduction of antenna gain. As $\sigma_{8}$ increases, the slope of the leading edge becomes shallower until no fall-off in the plateau region of the wave form is 


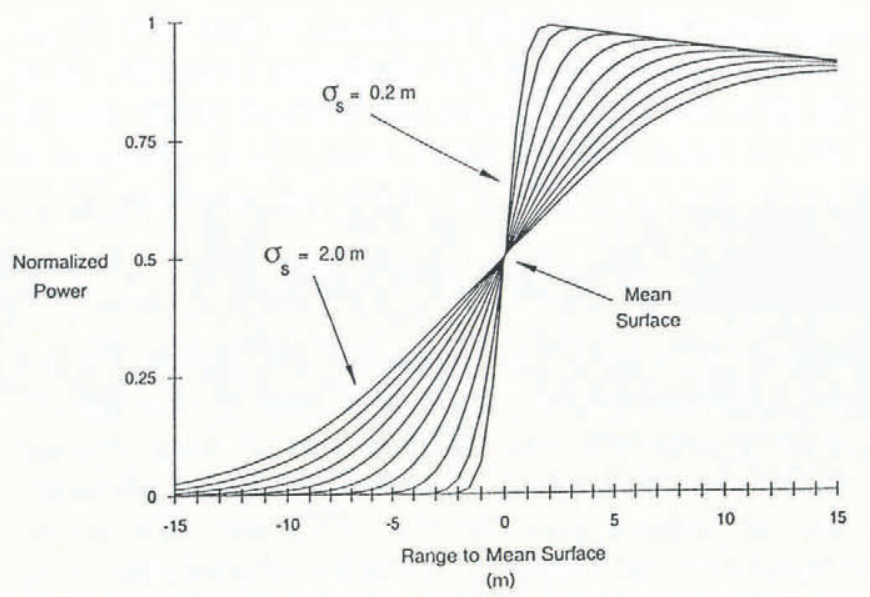

Fig. 2. Ocean surface-scattering altimeter wave forms from the Brown model for $\sigma_{\mathrm{s}}=0.2-2.0 \mathrm{~m}$.

apparent. Over the ocean, the wave-form's leading-edge width is used to estimate significant wave height (SWH) where

$$
\mathrm{SWH}=4 \sigma_{\mathrm{s}} .
$$

The satellite range to the mean sea surface is measured by tracking the half-power position on the leading edge of the wave form. Since the reflectivity of the ocean surface is nearly constant, the amplitude of the return wave form is used to estimate the surface wind speed. As surface winds increase, the ocean surface becomes rougher and fewer facets will contribute specularly reflected energy, causing a decrease in the overall wave-form amplitude. Over the last 15 years, various forms of the surface-scattering model have been used to study sea levels (e.g. Miller and others, 1986; Cheney and others, 1989), and wave-height/windspeed measurements were validated through comparison with in situ data (e.g. Fedor and others, 1979; Brown and others, 1981; Fedor and Brown, 1982; Dobson, 1987; Monaldo, 1988).

The on-board algorithm that estimates the satellite range tracks the half-power point on the leading edge of the return wave form (Fig. 2). The return wave form is digitized into equally spaced range "gates", where the center gate should coincide with the half-power point on the mean wave form. The design of the tracking algorithm is based upon the assumption that the range to the surface changes slowly and predictably with time. This is valid for the ocean surface, and the algorithm positions the center gate at the half-power point very accurately. However, over the ice sheets the half-power point deviates substantially from the center gate because of larger topographic variations. Since the telemetered range corresponds to the center gate, further processing on the ground is required to correct the range estimate for ice-sheet wave forms. This procedure is called "retracking". The retracking correction measures the distance from the center gate to the leading edge of the return wave form. All ice-sheet altimeter data must be retracked to produce accurate elevation measurements (Martin and others, 1983; Zwally and others, 1990), and one must apply further adjustments to correct for elevation errors caused by local surface slopes (Brenner and others, 1983).
The retracking algorithm used to correct range measurements over the ice sheet uses a modified form of Brown's analytical surface-scattering model (Zwally and others, 1990). The modified model includes a parameter that controls the trailing-edge slope of the return wave form to account for pointing-angle errors and ice-sheet slopes. In addition, a double-ramped form of the model is used to retrack complex wave forms that occur when two distinct and nearly equidistant surfaces contribute backscattered power within the sampled range of the altimeter. This modified version of the Brown model retracked all Seasat and Geosat ice-sheet wave forms to obtain the corrected surface elevations now archived at both the World Data Center for Glaciology in Boulder, Colorado, and at NASA/Goddard Space Flight Center in Greenbelt, Maryland.

Recent work by Ridley and Partington (1988) demonstrated that return wave forms from the ice sheets differed substantially from those predicted by the surfacescattering model in many cases. They proposed that volume-scattering from beneath the ice-sheet surface contributed substantially to the return power, and they developed a model based upon the numerical evaluation of an integral to describe the return wave forms. Based upon a qualitative analysis of averaged return wave forms, Partington and others (1989) showed that the shape of the altimeter wave forms from Greenland corresponded roughly to surface-scattering in the low latitudes and volume-scattering in the higher latitudes. They observed only subtle variations in the shape of the averaged wave forms from the Antarctic plateau regions. Moreoever, Davis and Poznyak (in press) showed that $10 \mathrm{GHz}$ radar signals can penetrate many meters below the ice-sheet surface of East Antarctica, and that the amount of penetration varied with surface elevation. Thus, sub-surface volume-scattering can contribute significant amounts of return energy at frequencies used by satellite altimeters.

The presence of volume-scattering suggests altimeter wave forms may contain important geophysical information about the surface conditions of the ice sheet. In this paper, we develop an analytical model that describes altimeter return wave forms from the continental ice sheets. Using Gaussian approximations for the altimeter's antenna pattern and transmitted pulse shape, we derive an analytical solution for the volume-scattering power from beneath the ice-sheet surface. Because a closed-form solution is obtained, we combine the volume-scattering model with the Brown surface-scattering model to develop a retracking algorithm that can be applied directly to individual altimeter return wave forms (Davis, in press). The term "individual wave forms" refers to wave forms telemetered from the satellite at a rate of $10 \mathrm{~s}^{-1}$, which are themselves an average of 100 returnpulse echoes.

By retracking individual wave forms, quantitative estimates of the geographic and seasonal variations in the near-surface properties of the ice sheet were determined (Davis and Zwally, 1993). These correlate well with elevation, latitude, mean annual temperature, etc. Furthermore, by comparing retracking locations on individual wave forms, the combined model can be used to assess the accuracy of surface elevations produced by 
various retracking algorithms. Seasonal variations in the amount of signal penetration could produce erroneous estimates of ice-sheet elevation change, especially with algorithms assuming only surface-scattering contributions to the return power. This needs to be evaluated to allow accurate detection of changes in the mass balance of the ice sheets by temporal studies of satellite cross-overs. This is extremely important for current and future altimeter missions that cover higher latitudes, where greater signal penetration is expected to occur.

\section{ALTIMETER WAVE-FORM MODEL}

For the Seasat and Geosat altimeters, each return wave form is an average of 100 return pulse echoes. The return wave form, elevation estimate and other geophysical parameters are telemetered at a rate of $10 \mathrm{~s}^{-1}$, which corresponds to a satellite traverse distance of $662 \mathrm{~m}$. The altimeter wave form is sampled within a range window that has a width of approximately $28 \mathrm{~m}$. Sub-surface volume-scattering contributes energy to the return wave form for depths up to approximately half the width of the range window. In geneneral, the material found within the top $15 \mathrm{~m}$ of the ice-sheet surface is a mixture of snow and firn. Firn is a term used for snow that has achieved a greater density $\left(>0.4 \mathrm{Mg} \mathrm{m}^{-3}\right)$ through recrystallization (Paterson, 1981). For simplicity, we use the term snow in this paper to describe the near-surface material, while recognizing that the density of this material is typically greater than that attributed to snow.

The geometry for an altimeter pulse that penetrates the ice-sheet surface is shown in Figure 3. The power density incident upon the snow surface is

$$
P_{\mathrm{i}}=\frac{P G}{4 \pi R^{2}} \quad \mathrm{Wm}^{-2}
$$

where $P$ is the transmitted power, $G$ is the antenna gain toward nadir and $R$ is the satellite range to the surface. The incident power is either scattered back from the

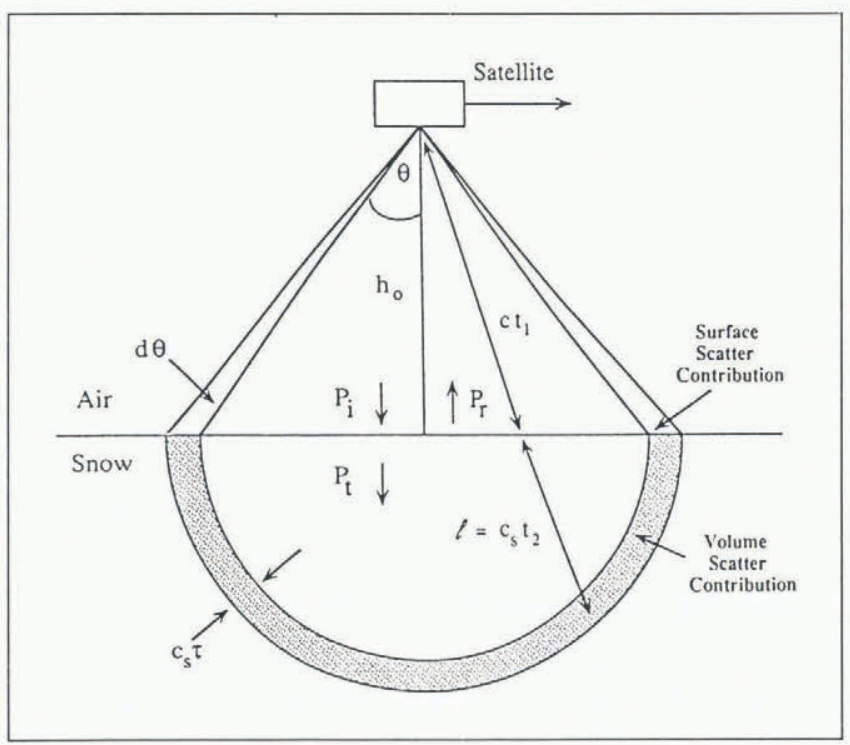

Fig. 3. Geometry for satellite-altimeter pulse that penetrates the ice-sheet surface producing volume scatter. surface toward the satellite or transmitted across the air/ snow boundary. The power transmitted across the air/ snow boundary can then be scattered back to the satellite by the ice crystals within the snow volume. When both surface- and volume-scattering are present, the surfacescattering strength is proportional to the relative complex dielectric constant, $\epsilon_{\mathrm{s}}$, at the surface, while the volumescattering strength is proportional to the dielectric discontinuities inside the medium and the density of the inhomogeneities (Ulaby and others, 1982, p. 846).

The signal strength after passing the air/snow boundary is

$$
P_{\mathrm{t}}=T P_{\mathrm{i}}
$$

where $T$ is the power-transmission coefficient at the surface and is related to the Fresnel reflection coefficient, $\Gamma$, by

$$
T=1-|\Gamma|^{2}
$$

where

$$
\Gamma=\frac{\sqrt{\epsilon_{\mathrm{s}}}-1}{\sqrt{\epsilon_{\mathrm{s}}}+1}
$$

and $\epsilon_{\mathrm{s}}$ is the relative dielectric constant of snow. Typical values for the real and imaginary parts of the relative dielectric constant, Fresnel reflection coefficient and power-transmission coefficient for dry snow, wet snow, ice and ocean water are shown in Table 1. For dry snow, wet snow and ice, the power-transmission coefficient is greater than $90 \%$. However, when only a small amount of water is contained in the snow, the imaginary part of the relative dielectric constant increases to a value that is hundreds of times larger than that for dry snow. For large values of the imaginary dielectric constant, the incident energy is severely attenuated because of high absorption losses. Thus, for wet snow, one expects surface-scattering to contribute most of the return power, while for dry snow

Table 1. Properties of snow, ice and ocean water at $13.5 \mathrm{GHz}$

\begin{tabular}{llllll}
\hline$\epsilon^{\prime}$ & $\epsilon^{\prime \prime}$ & $|\Gamma|$ & $|T|$ \\
\hline
\end{tabular}

Dry snow

$\begin{array}{lllll}\rho=0.40 \mathrm{Mg} \mathrm{m}^{-3} & 1.75 & 2 \times 10^{-4} & 0.14 & 0.98 \\ \rho=0.50 \mathrm{Mg} \mathrm{m}^{-3} & 2.00 & 4 \times 10^{-4} & 0.17 & 0.97\end{array}$

Wet snow

$\begin{array}{lllll}\rho=0.40 \mathrm{Mg} \mathrm{m}^{-3} & & & & \\ m_{\mathrm{v}}{ }^{*}=2.0 \% & 1.83 & 0.08 & 0.15 & 0.98 \\ m_{\mathrm{v}}{ }^{*}=5.0 \% & 2.02 & 0.27 & 0.18 & 0.97 \\ & & & & \\ \text { Ice } & 3.15 & 10^{-3} & 0.28 & 0.92 \\ & & & & \\ \text { Ocean water } & 78.0 & 43.0 & 0.81 & 0.35\end{array}$

${ }^{*} m_{\mathrm{v}}$, per cent water content by volume. 
it is clear that significant contributions from sub-surface volume-scattering is likely.

As the energy from the expanding spherical shell penetrates the snow surface, it is attenuated by the snow volume. The reduction in power density is defined by the equation

$$
\mathrm{d} P_{\mathrm{t}}=-k_{\mathrm{e}} P_{\mathrm{t}} \mathrm{d} \ell
$$

where $\mathrm{d} P_{\mathrm{t}}$ is the incremental attenuation of the incident power $P_{\mathrm{t}}, \ell$ is the path length in snow and $k_{\mathrm{e}}$ is the extinction coefficient of snow. The extinction coefficient describes the absorption and scattering losses within the snow volume. Separating variables, we obtain

$$
\frac{\mathrm{d} P_{\mathrm{t}}}{P_{\mathrm{t}}}=-k_{\mathrm{e}} \mathrm{d} \ell
$$

or

$$
\ln P_{\mathrm{t}}=-\int k_{\mathrm{e}} \mathrm{d} \ell
$$

and so

$$
P_{\mathrm{t}}(\ell)=P_{\mathrm{t}} \exp \left[-k_{\mathrm{e}} \ell\right] .
$$

This equation is commonly applied in radar-meteorology problems to describe the attenuation of the radar signal by clouds, rain, snow and hail (Battan, 1973; Ulaby and others, 1981).

The back-scattered power from the differential snow volume propagates back through the snow volume and is transmitted across the snow/air interface once more. The differential power just below the surface is

$$
\mathrm{d}^{3} \mathrm{P}_{\mathrm{r}}=T P_{\mathrm{t}} \sigma_{\mathrm{vs}} \exp \left(-2 k_{\mathrm{e}} \ell\right) \mathrm{dS} \mathrm{dR}
$$

where $\mathrm{d} S$ and $\mathrm{d} R$ are the differential shell area and thickness, $\sigma_{\mathrm{vg}}$ is the back-scattering cross-section per unit volume and the factor of two in the exponential accounts for the two-way attenuation of the signal through the snow. The differential received power at the altimeter is

$$
\mathrm{d}^{3} \mathrm{P}_{\mathrm{r}}=\frac{T P_{\mathrm{t}} \sigma_{\mathrm{vs}} A_{\mathrm{e}}}{4 \pi R^{2}} g^{2}(\theta) \exp \left(-2 k_{\mathrm{e}} \ell\right) \mathrm{d} S \mathrm{~d} R
$$

where $A_{\mathrm{e}}$ is the effective aperture of the antenna

$$
A_{\mathrm{e}}=\frac{G \lambda^{2}}{4 \pi}
$$

$g^{2}(\theta)$ is a function that describes the two-way angular variation of antenna gain and the $4 \pi R^{2}$ term accounts for the spreading loss of the re-radiated power. For spherical coordinates, the differential area is

$$
\mathrm{d} S=R^{2} \sin \theta \mathrm{d} \theta \mathrm{d} \psi
$$

and the differential thickness is

$$
\mathrm{d} R=c_{\mathrm{s}} \mathrm{d} t
$$

where $c_{B}$ is the speed of light in snow. From the geometry (Fig. 3), the path length in snow is a function of both angle and time

$$
\ell(\theta, t)=c_{s}\left(t-\frac{t_{0}}{\cos \theta}\right)
$$

where $t_{0}$ is the round-trip time corresponding to the initial intersection of the pulse shell with the flat surface

$$
t_{0}=\frac{2 h}{c} .
$$

Using a Gaussian approximation for the antenna pattern, we have

$$
g^{2}(\theta)=\exp \left(\frac{-\theta^{2}}{\beta^{2}}\right)
$$

where $\beta$ is a constant that determines the two-way antenna beam width and is given by

$$
\beta=\frac{\theta_{3 \mathrm{~dB}}}{\sqrt{-4 \ln 0.25}} .
$$

The Gaussian approximation is valid out to the point on the antenna pattern for which there is no appreciable contribution to the back-scattered power (Brown, 1977).

Substituting Equations (9), (10), (17)-(20) and (22) into Equation (16), we obtain

$$
\begin{gathered}
\mathrm{d}^{3} P_{\mathrm{r}}=A \sin \theta \exp \left(-2 k_{\mathrm{e}} c_{\mathrm{s}}\left(t-\frac{t_{0}}{\cos \theta}\right)\right) \\
\cdot \exp \left(\frac{-\theta^{2}}{\beta^{2}}\right) \mathrm{d} t \mathrm{~d} \theta \mathrm{d} \psi
\end{gathered}
$$

where $A$ is a term containing all constants and is given by

$$
A=\frac{P T^{2} \lambda^{2} G^{2} c_{\mathrm{s}} \sigma_{\mathrm{vs}}}{(4 \pi)^{3} R^{2}} .
$$

Assuming no azimuthal variations in the snow properties, the integration of Equation (24) in $\psi$ yields a factor of $2 \pi$. At any time $t>t_{0}$, the angle from nadir to the edge of the shell volume on the surface is a function of time and is given by

$$
\theta(t)=\cos ^{-1}\left(\frac{t_{0}}{t}\right),
$$

so that the integration of Equation (24) in $\theta$ becomes

$$
\begin{gathered}
\mathrm{d} P_{\mathrm{r}}=2 \pi A \int_{0}^{\cos ^{-1}\left(t_{0} / t\right)} \sin \theta \exp \left(-2 k_{\mathrm{e}} c_{\mathrm{s}}\left(t-\frac{t_{0}}{\cos \theta}\right)\right) \\
\cdot \exp \left(\frac{-\theta^{2}}{\beta^{2}}\right) \mathrm{d} \theta .
\end{gathered}
$$

This equation is simplified considerably by using the small-angle approximations

$$
\begin{aligned}
& \sin \theta \approx \theta \\
& \cos \theta \approx 1-\frac{\theta^{2}}{2} .
\end{aligned}
$$

For a flat surface, the maximum angle that contributes energy to the sampled return wave forms for the Seasat and Geosat altimeters is $\approx 0.4^{\circ}$, making these approximations extremely accurate. The equation is further simplified by converting to the two-way incremental ranging time, $\delta$, given by Equation (4). Making these substitutions into Equation (27), we obtain

$$
\begin{gathered}
\mathrm{d} P_{\mathrm{r}}=2 \pi A \int_{0}^{\sqrt{2 \delta^{\prime} / t_{0}}} \theta \exp \left(-2 k_{\mathrm{e}} c_{\mathrm{s}}\left(\delta^{\prime}-\frac{\theta^{2}}{2}\right)\right) \\
\cdot \exp \left(\frac{-\theta^{2}}{\beta^{2}}\right) \mathrm{d} \theta
\end{gathered}
$$


where $\delta^{\prime}$ is a dummy variable for $\delta$. Re-arranging terms in the exponential, we obtain

$$
\begin{aligned}
& \mathrm{d} P_{\mathrm{r}}=\pi A \exp \left(-2 k_{\mathrm{e}} c_{\mathrm{s}} \delta^{\prime}\right) \\
& \cdot \int_{0}^{\sqrt{2 \delta^{\prime} / t_{0}}} 2 \theta \exp \left(\theta^{2}\left[k_{\mathrm{e}} c_{\mathrm{s}} t_{0}-\frac{1}{\beta^{2}}\right]\right) \mathrm{d} \theta .
\end{aligned}
$$

Integrating Equation (30), we obtain

$$
\mathrm{d} P_{\mathrm{r}}=A^{\prime}\left\{\exp \left(\frac{-2 \delta^{\prime}}{t_{0} \beta^{2}}\right)-\exp \left(-2 k_{\mathrm{e}} c_{\mathrm{s}} \delta^{\prime}\right)\right\}
$$

where

$$
A^{\prime}=\frac{\pi A \beta^{2}}{k_{\mathrm{e}} c_{\mathrm{s}} t_{0} \beta^{2}-1} .
$$

The first exponential term in Equation (31) describes the effect of the altimeter's antenna pattern on the return power, while the second exponential term describes the effect of the signal attenuation caused by the propagation of the altimeter pulse through the snow. Note that $\mathrm{d} P_{\mathrm{r}}$ in Equation (31) is a function of time (range) and only applies for ranges beneath the ice-sheet surface $(\delta>0)$, where volume-scattering contributes to the received power. To obtain the total volume-scattered power as a function of time, we convolve the impulse response $\mathrm{d} P_{\mathrm{r}} / \mathrm{d} \delta$ in Equation (31) with the transmitted pulse profile (see Equation (1)), thus

$$
\begin{aligned}
P_{\mathrm{r}}(\delta)=A^{\prime} \int_{-\infty}^{\infty} & \left\{\exp \left(\frac{-2 \delta^{\prime}}{t_{0} \beta^{2}}\right)\right. \\
& \left.-\exp \left(-2 k_{\mathrm{e}} c_{\mathrm{s}} \delta^{\prime}\right)\right\} p\left(\delta-\delta^{\prime}\right) \mathrm{d} \delta
\end{aligned}
$$

For typical space-borne altimeters, the width of the transmitted pulse, $\tau$, is less than $10 \mathrm{~ns}$. The transmittedpulse shape is essentially a quadratic shape, but, for small pulse widths, can be adequately represented by a Gaussian function (Brown, 1977). Thus,

$$
p\left(\delta-\delta^{\prime}\right)=\exp \left(\frac{-\left(\delta-\delta^{\prime}\right)^{2}}{\beta_{\tau}{ }^{2}}\right)
$$

where $\beta_{\tau}$ is a constant that determines the $3 \mathrm{~dB}$ width of the transmitted pulse. Multiplying and regrouping the terms in the exponentials, we obtain an integral of the form

$$
\begin{aligned}
P_{\mathrm{r}}(\delta)=A^{\prime} \exp \left(\frac{-\delta^{2}}{\beta_{\tau}{ }^{2}}\right) \int_{-\infty}^{\infty} & \left\{\exp \left(-B{\delta^{\prime}}^{2}-C \delta^{\prime}\right)\right. \\
& \left.-\exp \left(-B{\delta^{\prime}}^{2}-D \delta^{\prime}\right)\right\} \mathrm{d} \delta
\end{aligned}
$$

where

$$
\begin{aligned}
& B=\frac{1}{\beta_{\tau}{ }^{2}}, \\
& C=\frac{2}{t_{0} \beta^{2}}-\frac{2 \delta}{\beta_{\tau}{ }^{2}}
\end{aligned}
$$

and

$$
D=2 k_{\mathrm{e}} c_{\mathrm{s}}-\frac{2 \delta}{\beta_{\tau}^{2}} .
$$

This is a tabulated integral (Gradshteyn and Ryzhik,
1980 , p. 307) and the final result for the received power due to volume-scattering is

$$
\begin{aligned}
P_{\mathrm{r}}(\delta) & =A^{\prime \prime}\left\{\exp \left(\frac{\beta_{\tau}{ }^{2}}{t_{0}{ }^{2} \beta^{4}}-\frac{2 \delta}{t_{0} \beta^{2}}\right)\right. \\
& \left.-\exp \left(\beta_{\tau}{ }^{2}{k_{\mathrm{e}}}^{2} c_{\mathrm{s}}{ }^{2}-2 k_{\mathrm{e}} c_{\mathrm{s}} \delta\right)\right\}
\end{aligned}
$$

where $A^{\prime \prime}$ is the amplitude in watts given by

$$
A^{\prime \prime}=\sqrt{\pi} \beta_{\tau} A^{\prime} .
$$

The closed-form analytical solution given by Equation (37) describes the average return power due to subsurface volume-scattering as a function of time. The constants in the argument of the first exponential function are determined by design characteristics of the altimeter, i.e. satellite height, antenna beam width and transmitted pulse width. In the second exponential function, the argument is controled by the geophysical paramters $k_{\mathrm{e}}$ and $c_{8}$, as well as by the width of the transmitted pulse. The most significant simplifying assumption in our derivation of the volume-scattering model is that the snowpack is homogeneous within the volume sampled by the altimeter. This allows the attenuation of the signal through the snow to be described by a constant extinction coefficient, and it permits the contribution of the differential shell volumes to the received power to be described by a constant back-scattering cross-section per unit volume. The volume-scattering model is a first-order approximation to the physical situation where the snow density and grain-sizes are known to increase with depth under typical ice-sheet conditions. The advantage of our approach is that we obtain a closed-form solution and can combine it with the Brown surface-scattering model. The combined model can be used to retrack individual altimeter wave forms over the ice sheets to obtain quantitative estimates of the near-surface geophysical properties of the ice sheet (Davis and Zwally, 1993).

Figure 4 shows a family of curves generated from the volume-scattering model. For small values of the extinction coefficient, $k_{\mathrm{e}}$, the wave forms rise slowly because an ever-increasing snow volume contributes to the return power as the signal penetrates many meters beneath the ice-sheet surface. For larger values of $k_{\mathrm{e}}$, the

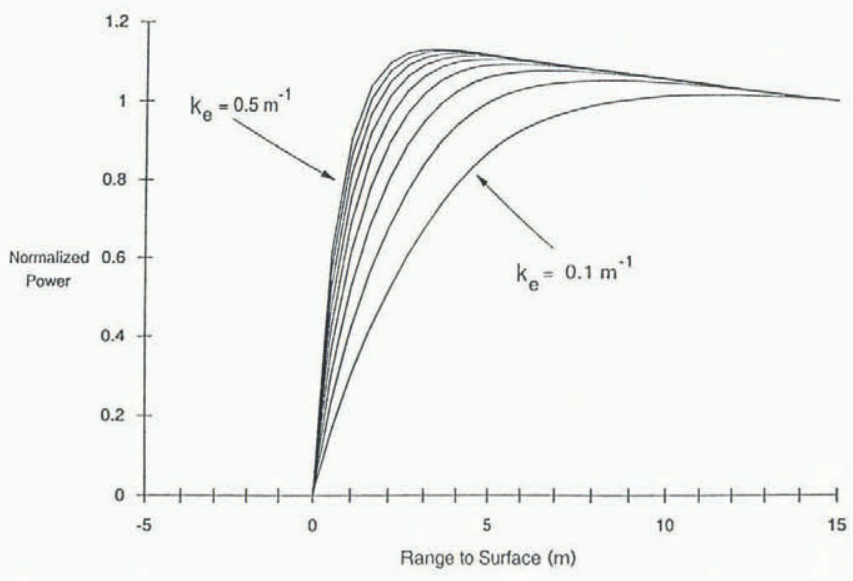

Fig. 4. Family of curves generated from the volumescattering model for $k_{\mathrm{e}}=0.1-0.5 \mathrm{~m}^{-1}$. 
signal penetration is reduced and the wave forms rise rapidly because most of the snow volume contributing to the return power is located near the ice-sheet surface. The depth of penetration, $d_{\mathrm{p}}$, is defined as the depth where the incident power density is reduced in magnitude to $1 / \mathrm{e}$. For an extinction coefficient that varies with depth $z, d_{\mathrm{p}}$ is defined by

$$
\int_{0}^{d_{\mathrm{p}}} k_{\mathrm{e}}\left(z^{\prime}\right) \mathrm{d} z^{\prime}=1
$$

while for a constant extinction coefficient this reduces to

$$
d_{\mathrm{p}}=\frac{1}{k_{\mathrm{e}}} .
$$

In the limit, as the extinction coefficient approaches infinity, the depth of penetration approaches zero and only surface-scattering contributes to the back-scattered power. Note that, for the wave forms with large values of $k_{\mathrm{e}}$, the fall-off in the plateau region due to the antenna pattern is present and the wave forms are similar to those generated by the Brown surface-scattering model (Fig. 2).

The volume-scattering model is combined with the Brown surface-scattering model in the following form

$$
S V(\delta)=S(\delta)+K V(\delta)
$$

where $S(\delta)$ is the Brown model (Equation (2)), $V(\delta)$ is the volume-scattering model (Equation (37)) and $K$ is the volume-scattering coefficient. The volume-scattering coefficient describes the magnitude of the volumescattered power relative to the surface-scattered power. The inclusion of the surface-scattering model is necessary for two reasons. First, because a flat surface is assumed in the derivation of the volume-scattering model, the effects of surface roughness must be taken into account to obtain realistic altimeter return wave forms. As surface roughness increases, the width of the wave-form's leading edge increases, just as in the case of surface-scattering over the ocean. Secondly, the surface area that contributes backscattered power increases linearly up to the point when the trailing edge of the pulse intersects the surface, where the region back-scattering energy to the satellite becomes an expanding annulus of constant area. However, the volume that contributes to the back-scattered power increases linearly (approximately) throughout the entire range sampled by the altimeter. When the amount of surface- and volume-scattering is nearly equal, an initial sharp increase in return power occurs. This corresponds to the linear increase in surface area and sampled volume. However, once the surface area becomes constant, the volume that contributes back-scattered power still increases so the return power continues to increase but at a reduced rate. Thus, when the combined model is fitted to altimeter wave forms, the parameter $K$ provides an indication of the relative contribution of the volumescattered power.

\section{APPLICATIONS}

Although the primary purpose of this paper is to present the above concepts and formulas, in this section we fit the combined model to Geosat-altimeter data to demonstrate the variations in the shape of the return wave forms that occur over the Greenland and Antarctic ice sheets. In addition, we use the combined model to simulate the effect of different antenna beam widths and operating frequencies on the shape of the return wave forms over the ice sheets. The results show that two-frequency altimeters can provide information to separate the different absorption and scattering losses from the extinction coefficient.

\section{Averaged wave-form analysis}

For the Geosat satellite, each telemetered wave form is an average of 100 pulse echoes. The telemetered wave forms experience noisy fluctuations in the plateau region following the initial rise of the leading edge. Both the surface- and volume-scattering models describe the mean received power, whereas return wave forms fluctuate about the mean because of fading, surface geometry and inhomogeneities. We selected three $30 \mathrm{~km}$ by $50 \mathrm{~km}$ areas on the Greenland and Antarctic ice sheets where the physical conditions of the surface should vary dramatically because of differences in latitude and elevation. For each area, 100-200 telemetered wave forms, corresponding to 10-15 different satellite tracks, were averaged together to reduce return-power fluctuations in the plateau region of the wave form.

The resulting mean wave forms are shown in Figure 5. They show the effect of varying contributions of surfaceand volume-scattering on the shape of the altimeter wave forms. The averaged wave form in Figure $5 \mathrm{a}$ is from an area around $65.0^{\circ} \mathrm{N}$ on the central part of the Greenland ice sheet. The wave form rises rapidly to a peak value and then falls off due to the altimeter's antenna pattern. This wave form is typical of a return that is dominated by surface-scattering and is in a region that frequently experiences surface melting during the summer (Davis and Zwally, 1993). The wave form in Figure 5b is from the Wilkes Land region of East Antarctica and is typical of a return that is dominated by volume-scattering. The return power continues to rise within the sampled range as the volume contributing to the back-scattered power increases with time. The wave form in Figure $5 \mathrm{c}$ is from an area around $72.0^{\circ} \mathrm{N}$ on the central part of the Greenland ice sheet. This wave form is typical of a return that is a combination of both surface- and volumescattering. The wave-form's leading edge initially rises very rapidly. At approximately the half-power point, the slope changes and the received power continues to increase but at a reduced rate. The initial rise corresponds to the linear increase in the surface area and volume that contributes to the back-scattered power. Once the surface area reaches a maximum value, the slower rise in return power corresponds to the expanding volume that continues to increase throughout the entire range sampled by the altimeter.

The model parameters that characterize the shape of altimeter wave forms are surface roughness, volume coefficient and extinction coefficient. The surface roughness, $\sigma_{8}$, controls the width of the leading edge of the wave form when surface-scattering is present. The volume coefficient, $K$, controls the relative contribution of the volume-scattered power to the received power. The 

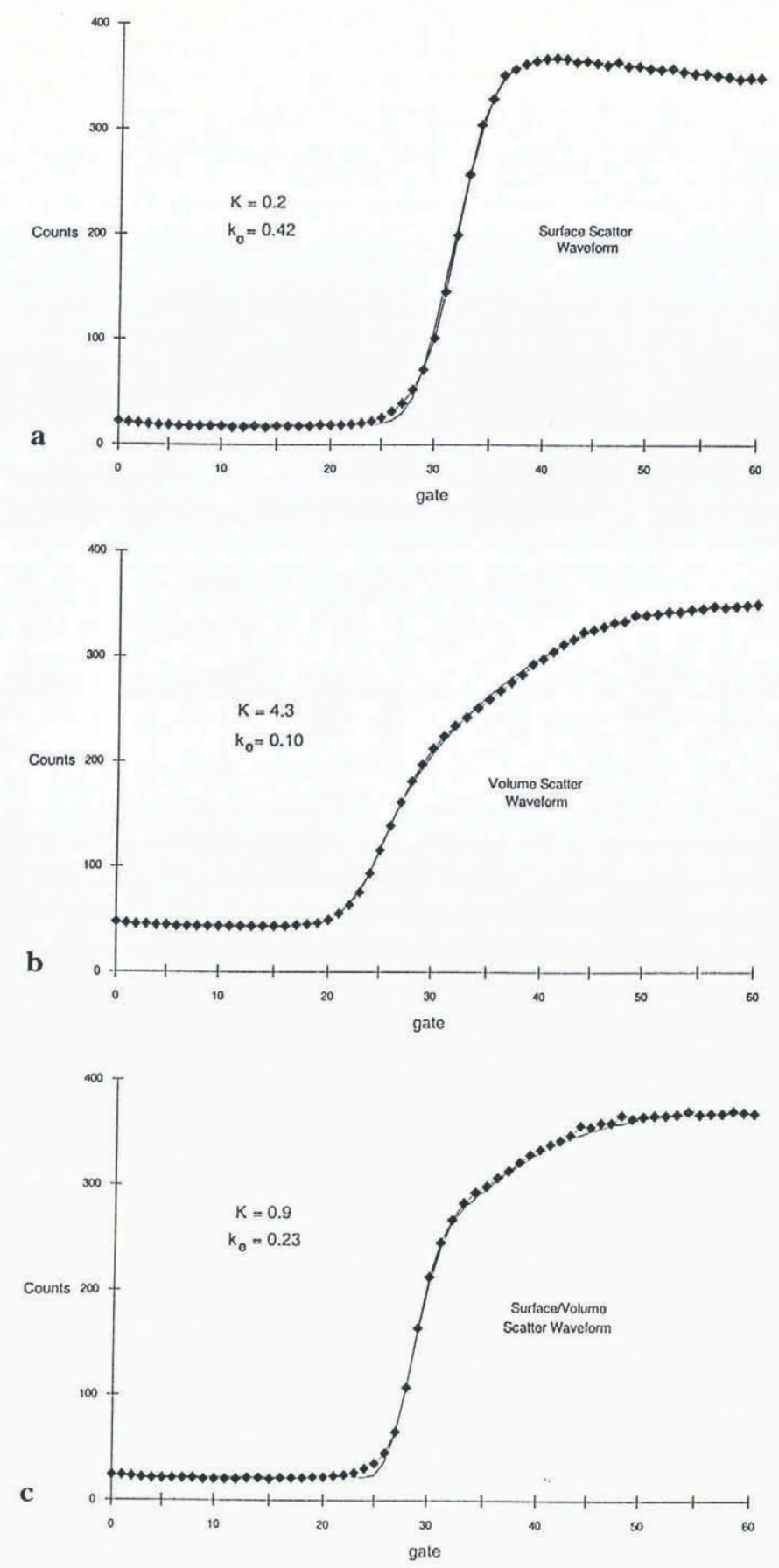

Fig. 5. Averaged Geosat altimeter return-wave forms (diamonds) and combined model fit (line). a. Surfacescattering wave form from Greenland ice sheet $\left(65.0^{\circ} \mathcal{N}\right.$, $\left.315^{\circ} \mathrm{E}\right)$. b. Volume-scattering wave form from Wilkes Land in East Antarctica $\left(72.0^{\circ} \mathrm{S}, 100^{\circ} \mathrm{E}\right)$. c. Combined surface-/volume-scattering wave form from Greenland ice sheet $\left(72.0^{\circ} \mathcal{N}, 316^{\circ} \mathrm{E}\right)$.

extinction coefficient, $k_{\mathrm{e}}$, controls the rate that the return power increases when volume-scattering is present. Increasing values of $k_{\mathrm{e}}$ cause the return power to rise more rapidly. The values of $K$ and $k_{\mathrm{e}}$ are used to distinguish between the three different types of return wave forms. For surface-scattering, the volume coefficient is less than 1.0, and the extinction coefficient is greater than $0.3 \mathrm{~m}^{-1}$. For volume-scattering, the volume coefficient is greater than 2.0 and the extinction coefficient is less than $0.2 \mathrm{~m}^{-1}$. For intermediate wave forms, the volume and extinction coefficients range between 1.0-
2.0 and $0.1-0.3 \mathrm{~m}^{-1}$, respectively. These parameter ranges are general values that help classify altimeter return wave forms into one of the three different scattering categories.

\section{Wave-form simulation}

The Topex-altimeter design actually contains two altimeters: a primary Ku-band altimeter and a secondary C-band altimeter. The purpose of the dual-frequency design is to provide path-length corrections to the altimeter-range measurements. Electrons in the ionosphere introduce a group delay in the altimeter pulse that is proportional to the columnar electron content and the inverse square of the pulse frequency. The dual-frequency system provides a sub-decimeter range precision, so that small dynamic variations in the ocean-surface topography can be measured.

Over the ice sheets, a dual-frequency altimeter will provide additional information about the physical properties of the near-surface snow. The volume-scattering model is controled by the rate at which the incident energy is attenuated as it propagates through the snow. The power lost from the incident energy is absorbed by the ice crystals, scattered or both. The absorption loss describes the transformation of the radar wave into other forms of energy such as heat, while the scattering loss describes energy that is scattered in directions other than that of the incident radiation. The absorption and scattering losses are linear processes and combine to form the extinction coefficient

$$
k_{\mathrm{e}}=k_{\mathrm{a}}+k_{\mathrm{s}} .
$$

For a dry-snow medium, the absorption coefficient dominates the extinction loss for frequencies below about $5 \mathrm{GHz}$, while for frequencies above $20 \mathrm{GHz}$ the scattering coefficient dominates (Ulaby and others, 1986, p. 1606). Since the Seasat and Geosat altimeters operate at $13.5 \mathrm{GHz}$, it is reasonable to expect that both scattering and absorption losses contribute to the total extinction for this frequency.

The absorption coefficient for snow is determined by its dielectric properties (Stiles and Ulaby, 1981)

$$
k_{\mathrm{a}}=\frac{4 \pi f}{c}\left\{\frac{\epsilon_{\mathrm{ds}}^{\prime}}{2}\left[\sqrt{1+\left(\frac{\epsilon_{\mathrm{ds}}^{\prime \prime}}{\epsilon_{\mathrm{ds}}^{\prime}}\right)^{2}}-1\right]\right\}^{\frac{1}{2}}
$$

where $\epsilon_{\mathrm{ds}}^{\prime}$ and $\epsilon_{\mathrm{ds}}^{\prime \prime}$ are the real and imaginary parts of the complex dielectric constant of dry snow. When small amounts of water are present in the snow, the imaginary part of the dielectric constant increases substantially (Hallikainen and others, 1986), causing a large increase in the absorption coefficient. When surface melting occurs on the ice sheets, the depth of penetration is substantially reduced because the high absorption losses mask any back-scattered energy from below (Ulaby and others, 1982 , p. 850). Thus, surface-scattering dominates the altimeter return wave form when melting occurs. Note also that the absorption coefficient is linearly related to the altimeter's operating frequency.

The Rayleigh scattering coefficient for snow is

$$
k_{\mathrm{s}}=32\left(\frac{\pi f}{c}\right)^{4} \frac{\rho_{\mathrm{s}}}{\rho_{\mathrm{i}}} r^{3}\left|\frac{\epsilon_{\mathrm{i}}-1}{\epsilon_{\mathrm{i}}+2}\right|^{2}
$$


where $\rho_{\mathrm{s}}$ and $\rho_{\mathrm{i}}$ are the density of snow and ice, $r$ is the radius of the ice grains and $\epsilon_{\mathrm{i}}$ is the complex dielectric constant of ice. The magnitude of the scattering coefficient is very sensitive to the grain-size/wavelength ratio and, for a constant grain-size, the scattering is proportional to the fourth power of frequency. A limitation of the Rayleigh-scattering model is that it assumes independent spherical scattering centers. Because snow is a dense medium, multiple-scattering interactions occur, causing the Rayleigh-scattering coefficient to overestimate the true scattering loss. Comiso and others (1982) multiplied $k_{\mathrm{B}}$ by the empirical parameter $f_{\mathrm{d}}=0.3$ to acount for the overestimation of the Rayleighscattering model when they used the radiative-transfer method to investigate emissivities from the Antarctic ice sheet. This dense-medium coefficient, $f_{\mathrm{d}}$, is used in our simulation of the altimeter wave forms over the ice sheet to generate approximate values for the scattering coefficient of dry snow.

Since the scattering coefficient has a greater frequency dependence, altimeter return wave forms from a twofrequency system provide additional information, so that absorption and scattering contributions may be separated from the extinction coefficient. To simulate the return wave forms from a two-frequency system, the Topexaltimeter design parameters shown in Table 2 are used in

Table 2. Space-borne altimeter characteristics

\begin{tabular}{lccc}
\hline & Seasat & Geosat & Topex \\
\hline Year & 1978 & 1985 & 1993 \\
& & & \\
Frequency (GHz) & 13.5 & 13.5 & $13.6 / 5.3$ \\
Pulse width (ns) & 3.2 & 3.2 & 3 \\
Peak power (W) & 2000 & 20 & $20 / 20$ \\
Range precision (cm) & 10 & 10 & 2.5 \\
3dB beam width (deg) & 1.6 & 2.0 & $1.1 / 2.7$ \\
Range window (m) & 28 & 28 & 60 \\
& & & \\
\hline
\end{tabular}

the combined model to simulate the ice-sheet wave forms. Because the same antenna is used by both the $\mathrm{C}$ - and $\mathrm{Ku}$ band altimeters, the antenna beam width at $\mathrm{C}$ band is more than twice that of the Ku-band beam width due to the smaller aperture/wavelength ratio. The effect of the different beam widths is shown in Figure 6 where the Brown surface-scattering model is used to generate the return wave forms. Because of the narrower beam width, the $\mathrm{Ku}$-band wave form has a larger decay rate in the plateau region compared to the C-band wave form. Note also that the altimeter-range window for the Topex altimeter is more than twice that of the Seasat and Geosat range windows.

Using mean values of $0.4 \mathrm{Mg} \mathrm{m}^{-3}$ and $0.7 \mathrm{~mm}$ for the snow density and grain-size, the absorption and scattering coefficients are calculated at $\mathrm{Ku}$ and $\mathrm{C}$ bands to determine the total rate of extinction. For the $\mathrm{Ku}$ - and

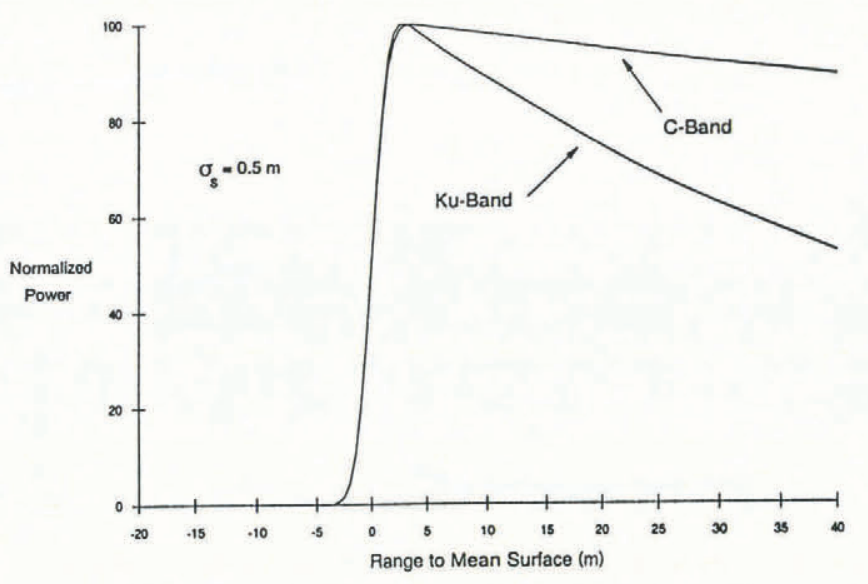

Fig. 6. Brown surface-scattering mean wave forms demonstrating the effect of different altimeter beam widths at $K u$ and $C$ bands on the decay rate in the plateau region of the wave form.

C-band frequencies, the extinction coefficients are 0.163 and $0.024 \mathrm{~m}^{-1}$, corresponding to the penetration depths of 6.1 and $41.6 \mathrm{~m}$, respectively. Then, using an r.m.s. surface roughness of $0.5 \mathrm{~m}$ and a volume coefficient of 3.0 , altimeter wave forms for each frequency are simulated using the combined surface-/volume-scattering model. The resulting mean wave forms are shown in Figure 7. The C-band wave form differs substantially from its surface-scattering counterpart because of the wide antenna beam width and low extinction coefficient. These two factors combine to produce a return wave form that never reaches a peak value in the sampled range of the altimeter. Because of the large depth of penetration at $\mathrm{C}$ band, the volume-scattered power contributes to the received power throughout the entire range sampled by the altimeter. The two Ku-band wave forms are more similar because of a narrower antenna beam width and larger extinction coefficient. A plot showing the combined model and surface-scattering model wave forms at $\mathrm{Ku}$ band is shown in Figure 8. Although the two wave forms are similar, the sub-surface

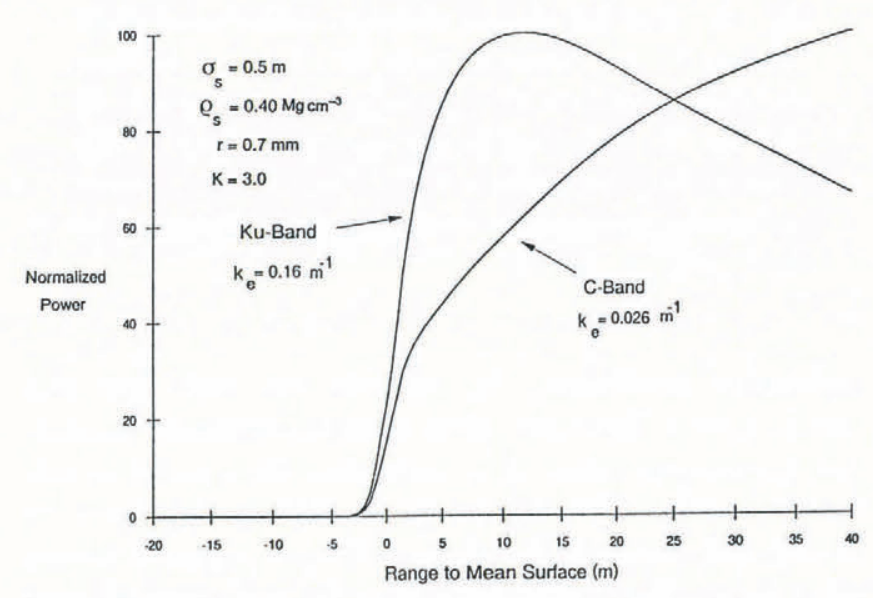

Fig. 7. Mean altimeter wave forms at $K u$ and $C$ bands generated by the combined surface-/volume-scattering model for calculated values of the extinction coefficient. Note that the C-band wave form differs substantially from its surface-scattering counterpart shown in Figure 6 . 


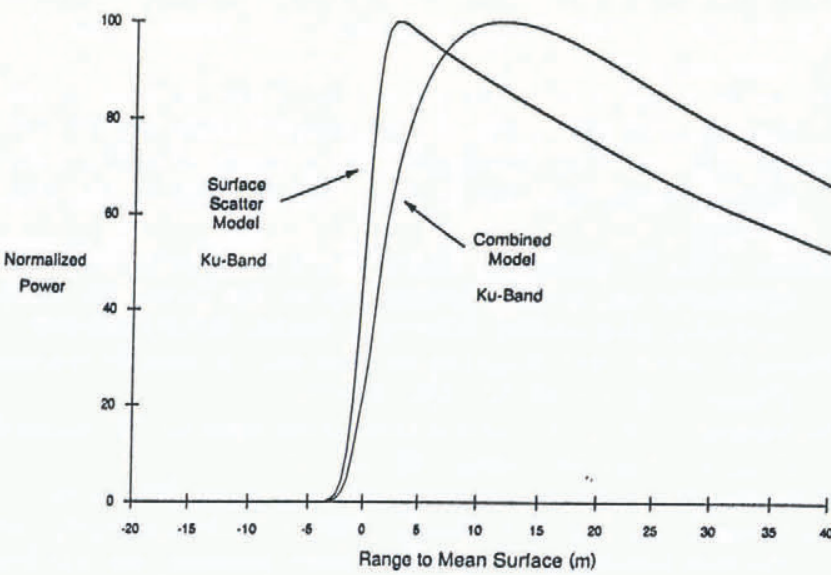

Fig. 8. Mean wave forms from surface-scattering and combined model at $K u$ band. Note that sub-surface volumescattering causes the peak in the wave-form amplitude to be delayed in time (range) compared to the surface-scattering wave form.

volume-scattering causes the peak amplitude to be delayed in time (range) compared to the peak amplitude of the surface-scattering wave form. Note also that the decay rate in the plateau region of each wave form is the same because the antenna beam width reduces the return power from surface- and volume-scattering at the same rate.

The difference in shape between the wave forms in Figure 7 is due to the large difference between the scattering coefficients at $\mathrm{Ku}$ and $\mathrm{C}$ bands. Because the scattering loss is much less than the absorption loss at $\mathrm{C}$ band, the value of the extinction coefficient from the combined model can be used to obtain an estimate of the absorption coefficient at $\mathrm{C}$ band. Next, using the linear dependence of $k_{\mathrm{a}}$ with frequency, an estimate of the absorption coefficient at $\mathrm{Ku}$ band can be calculated. This absorption coefficient can then be subtracted from the extinction coefficient value at $\mathrm{Ku}$ band to obtain an estimate of the scattering coefficient. The absorption and scattering losses are directly related to the density and grain-size distributions of the near-surface snow. Thus, dual-frequency altimeter measurements have the potential for providing quantitative estimates of snow densities and grain-sizes over the ice sheets.

\section{SUMMARY AND DISCUSSION}

A theoretical model describing the volume-scattered power for ice-sheet altimetry is derived assuming Gaussian distributions for the antenna pattern and transmitted pulse shape. The volume-scattering model is combined with the Brown surface-scattering model and applied to averaged return wave forms from the Greenland and Antarctic ice sheets. The results show that the return wave forms are characterized by varying amounts of surface- and volume-scattering. The volume coefficient, $K$, and extinction coefficient, $k_{\mathrm{e}}$, are used to classify the return wave forms into one of three categories: surfacescattering, volume-scattering or a combination of the two. In general, surface-scattering is predominant in the lowaltitude regions of the Greenland ice sheet, while varying combinations of surface- and volume-scattering occur at higher altitudes on the Greenland ice sheet. In the plateau region of East Antarctica, volume-scattering is the greatest contributor to the received power.

The presence of volume-scattering from the ice sheets suggests that important geophysical information concerning the near-surface conditions of the ice sheet can be derived from altimeter return wave forms. Because we obtain a closed-form analytical solution, the combined surface-/volume-scattering model can be used to retrack individual altimeter wave forms over the ice sheets. By retracking individual altimeter wave forms, quantitative estimates of the geographic and seasonal variations in the extinction coefficient of snow were determined and found to correlate well with elevation and latitude (Davis and Zwally, 1993). The retracking algorithm used to extract surface elevations from Seasat and Geosat is based upon the Brown surface-scattering model (Martin and others, 1983). Hence, it is important to determine the effect of sub-surface volume-scattering on the precision of these elevation measurements, so that repeated altimeter mapping of surface elevations can accurately detect changes in the mass balance of the ice sheets.

\section{ACKNOWLEDGEMENTS}

The first author (C.H.D.) was supported by the NASA graduate student fellowship program grant No. GSRPNGT-50464.

\section{REFERENCES}

Barnett, T.P. 1984. The estimation of "global" sea level change: a problem of uniqueness. J. Geophys. Res., 89(C5), 7980-7988.

Barrick, D. E. 1972. Remote sensing of sea state by radar. In Derr, V., ed. Remote sensing of the troposphere. Washington, DC, U.S. Government Printing Office.

Battan, L.J. 1973. Radar observation of the atmosphere. Chicago, IL, University of Chicago Press.

Bindschadler, R.A. 1984. Jakobshavns glacier drainage basin: a balance assessment. F. Geophys. Res., 89(C2), 2066-2072.

Bindschadler, R. A., H.J. Zwally, J. A Major and A. C. Brenner. 1989. Surface topography of the Greenland ice sheet from satellite radar altimetry. Washington, DC, National Aeronautics and Space Administration. (NASA SP-503.)

Brenner, A. C., R.A. Bindschadler, R.H. Thomas and H.J. Zwally. 1983. Slope-induced errors in radar altimetry over continental ice sheets. J. Geophys. Res., 88(C3), 1617-1623.

Brooks, R. L. 1982. Satellite altimeter results over East Antarctica. Ann. Glaciol., 3, 32-35.

Brooks, R. L. and G.A. Norcross. 1984. Ice sheet surface features from satellite radar altimetry. Mar. Geod., 8, 211-220.

Brooks, R. L., W.J. Campbell, R. O. Ramseier, H. R. Stanley and H.J. Zwally. 1978. Ice sheet topography by satellite altimetry. Nature, 274(5671), 539-543.

Brown, G. S. 1977. The average impulse response of a rough surface and its applications. IEEE Trans. Antennas Propag., 25, 67-74.

Brown, G.S., H.R. Stanley and N.A. Roy. 1981. The wind-speed measurement capability of spaceborne radar altimeters. IEEE 7. Oceanic Eng., 6, 59-63.

Bryan, K. and others. 1982. Transient climate response to increasing atmospheric carbon dioxide. Science, 215, 56-58.

Cheney, R. E., L. Miller, R. W. Agreen, N. S. Doyle and B. C. Douglas. 1989. Monitoring tropical sea level in near-real time with Geosat altimetry. Johns Hopkins APL Technical Digest, 10, 362-367.

Comiso, J. C., H.J. Zwally and J.L. Saba. 1982. Radiative transfer modeling of microwave emission and dependence on firn properties. Ann. Glaciol., 3, 54-58. 
Cudlip, W. and N. F. McIntyre. 1987. Seasat altimeter observations of an Antarctic 'lake'. Ann. Glaciol., 9, 55-59.

Davis, C.H. In press. A surface and volume-scattering retracking algorithm for ice sheet satellite altimetry. IEEE Trans. Geosci. Remote Sensing.

Davis, C. H. and V. I. Poznyak. In press. The depth of penetration in Antarctic firn at $10 \mathrm{GHz}$. IEEE Trans. Geosi. Remote Sensing.

Davis, C. H. and H.J. Zwally. 1993. Geographic and seasonal variations in the surface properties of the ice sheets by satellite-radar altimetry. 7. Glaciol., 39(133), 687-697.

Dobson, E. B. 1987. Wind and wave statistics as derived from the GEOSAT radar altimeter and comparisons with in situ measurements. Digest IGARSS' 87,1 , 245-249.

Etkins, R. and E. Epstein. 1982. The rise of global mean sea level as an indication of climate change. Science, 215(4530), 287-289.

Fedor, L. S. and G.S. Brown. 1982. Waveheight and windspeed measurements from the SEASAT radar altimeter. 7. Geophys. Res., 87, 3254-3260.

Fedor, L. S. and 6 others. 1979. Satellite altimeter measurements of sea state - an algorithm comparison. 7. Geophys. Res., 84(B8), 3991-4001.

Gradshteyn, I.S. and I. M. Ryzhik. 1980. Tables of integrals, series, and products. San Diego, CA, Academic Press.

Hallikainen, M. T., F.T. Ulaby and M. Abdelrazik. 1986. Dielectric properties of snow in the 3 to $37 \mathrm{GHz}$ range. IEEE Trans. Antennas Propag., 34, 1329-1336.

Hancock, D. W., R. G. Forsythe and J. Lorell. 1980. SEASAT altimeter sensor file algorithms. IEEE f. Oceanic Eng., 5, 93-99.

Hansen, J. and 6 others. 1988. Global climate changes as forecast by Goddard Institute for Space Studies three-dimensional model. 7. Geophys. Res., 93(D8), 9341-9364.

Hayne, G.S. 1981. Radar altimeter waveform model parameter recovery. Washington, DC, National Aeronautics and Space Administration. (NASA Tech. Memo. 73294.)

MacArthur, J.L. 1978. Seasat-A radar altimeter design description. Laurel, MD, Applied Physics Laboratory. (SDO-5232.)

MacArthur, J.L. and others. 1987. The Geosat radar altimeter. Fohns Hopkins APL Technical Digest, 8, 176-181.

Martin, T. V., H.J. Zwally, A.C. Brenner and R.A. Bindschadler. 1983. Analysis and retracking of continental ice sheet radar altimeter waveforms. 7. Geophys. Res., 88(C3), 1608-1616.

Mercer, J.H. 1978. West Antarctic ice sheet and $\mathrm{CO}_{2}$ greenhouse effect: a threat of disaster. Nature, 271(5643), 321-325.

Miller, L., R. Cheney and D. Milbert. 1986. Sea level time series in the equatorial Pacific from satellite altimetry. Geophys. Res. Lett., 13(5), 475-478.

Monaldo, F. 1988. Expected differences between buoy and radar altimeter estimates of wind speed and significant wave height and their implications on buoy-altimeter comparisons. J. Geophys. Res., 93(C3), 2285-2302.

Moore, R. K. and C.S. Williams. 1957. Radar return at near-vertical incidence. Proc. IRE, 45, 228-238.

Nye, J.F., Chairman. 1975. Symposium on Remote Sensing in Glaciology. General discussion. F. Glaciol., 15(73), 437-453.

Partington, K. C., W. Cudlip, N. F. McIntyre and S. King-Hele. 1987. Mapping of Amery Ice Shelf, Antarctica, surface features by satellite altimetry. Ann. Glaciol., 9, 183-188.

Partington, K. C., H.J. Zwally, J.K. Ridley and C. Rapley. 1989. Observations of the surface properties of the ice sheets by satellite radar altimetry. F. Glaciol., 35(120), 267-275.
Paterson, W. S. B. 1981. The physics of glaciers. Second edition. Oxford, etc., Pergamon Press.

Peltier, W.R. and A.M. Tushingham. 1989. Global sea level rise and the greenhouse effect: might they be connected? Science, 244, 806-810.

Ridley, J.K. and K. C. Partington. 1988. A model of satellite radar altimeter return from the ice sheets. Int. F. Remote Sensing, 9(4), 601-624.

Ridley, J.K., W. Cudlip, N. McIntyre and C. Rapley. 1989. The topography and surface characteristics of the Larsen Ice Shelf, Antarctica, using satellite altimetry. F. Glaciol., 35(121), 299-310.

Robin, G.de Q 1966. Mapping the Antarctic ice sheet by satellite altimetry. Can. F. Earth Sci., 3(6), 893-901.

Schlesinger, M.E. 1984. Climate model simulations of $\mathrm{CO}_{2}$ induced climatic change. Adv. Geophys., 26, 141-235.

Schneider, S. H. 1989. The changing climate. Sci. Am., 261, 70-79.

Stephenson, S.N. and H.J. Zwally. 1989. Ice-shelf topography and structure determined using satellite-radar altimetry and Landsat imagery. Ann. Glaciol., 12, 162-169.

Stiles, W.H. and F.T. Ulaby. 1981. Dielectric properties of snow. Lawrence, KS, University of Kansas. (RSL TR-527-1.)

Thomas, R. H. 1991. Polar research from satellites. Washington, DC, Joint Oceanographic Institutions, Inc.

Thomas, R.H., T.J. O. Sanderson and K.E. Rose. 1979. Effect of climatic warming on the West Antarctic ice sheet. Nature, 277(5695), 355-358.

Thomas, R. H., T. V. Martin and H.J. Zwally. 1983. Mapping ice-sheet margins from radar altimetry data. Ann. Glaciol., 4, 283-288.

Thomas, R. H. and 8 others. 1985. Satellite remote sensing for ice sheet research. Washington, DC, National Aeronautics and Space Administration. (NASA Tech. Memo. 86233.)

Townsend, W.F. 1980. An initial assessment of the performance achieved by the Seasat-1 altimeter. IEEE 7. Oceanic Eng., 5, 80-92.

Ulaby, F. T., R.K. Moore and A. K. Fung. 1981. Microwave remote sensing. 1. Reading, MA, Addison-Wesley Publishing Co.

Ulaby, F.T., R. K. Moore and A. K. Fung. 1982. Microwave remote sensing. 2. Dedham, MA, Artech House.

Ulaby, F.T., R.K. Moore and A.K. Fung. 1986. Microwave remote sensing. 3. Dedham, MA, Artech House.

Zwally, H.J. 1989. Growth of Greenland ice sheet: interpretation. Science, 246(4937), 1589-1591.

Zwally, H.J., R.A. Bindschadler, A. C. Brenner, T.V. Martin and R. H. Thomas. 1983. Surface elevation contours of the Greenland and Antarctic ice sheets. F. Geophys. Res., 88(C3), 1589-1596.

Zwally, H.J., S. N. Stephenson, R. A. Bindschadler and R. H. Thomas. 1987. Antarctic ice-shelf boundaries and elevations from satellite radar altimetry. Ann. Glaciol., 9, 229-235.

Zwally, H.J., A.C. Brenner, J.A. Major, R.A. Bindschadler and J. G. Marsh. 1989. Growth of Greenland ice sheet: measurement. Science, 246(4937), 1587-1589.

Zwally, H.J., A.C. Brenner, J.A. Major, T.V. Martin and R. A. Bindschadler. 1990. Satellite radar altimetry over ice. Vol. 1 . Processing and corrections of Seasat data over Greenland. Washington, DC, National Aeronautics and Space Administration. (NASA Ref. Pub. 1233.1.)

The accuracy of references in the text and in this list is the responsibility of the authors, to whom queries should be addressed. 